\title{
The Neuroprotective Activity of Group-II Metabotropic Glutamate Receptors Requires New Protein Synthesis and Involves a Glial- Neuronal Signaling
}

\author{
Valeria Bruno, ${ }^{1}$ Francesc X. Sureda, ${ }^{1}$ Marianna Storto, ${ }^{1}$ Giacomo Casabona, ${ }^{1}$ Alessandra Caruso, ${ }^{2}$ \\ Thomas Knopfel, ${ }^{3}$ Rainer Kuhn, ${ }^{4}$ and Ferdinando Nicoletti ${ }^{1,3}$ \\ 1. N. M. Neuromed, Pozzilli, Italy, 2 Institute of Biochemistry, School of Medicine, and 3/nstitute of Pharmacology, School \\ of Pharmacy, University of Catania, 95125 Catania Italy, and ${ }^{4}$ CNS Department, Ciba Research Laboratories, \\ Basel, Switzerland
}

\begin{abstract}
The group-II metabotropic glutamate (mGlu) receptor agonists (2S, 1'R,2'R,3'R)-2-(2,3-dicarboxycyclopropyl)glycine (DCG-IV), S-4-carboxy-3-hydroxyphenylglycine (4C3HPG), and (2S,1'S,2'S)2-(carboxycyclopropyl)glycine (L-CCG-I) protected mouse cortical neurons grown in mixed cultures against excitotoxic degeneration induced by a 10 min pulse with NMDA. Protection was observed not only when agonists were added in combination with NMDA but also when they were transiently applied to cultures 6-20 hr before the NMDA pulse. In both cases, neuroprotection was reduced by the group-II mGlu receptor antagonist (2S,1'S,2'S,3'R)2-(2'-carboxy-3'-phenylcyclopropyl)glycine (PCCG-IV), as well as by the protein synthesis inhibitor cycloheximide (CHX). Both neurons and astrocytes in mixed cultures were immunostained with an antibody that recognized mGlu2 and mGlu3 receptors in recombinant cells. To determine whether astrocytes played any role
\end{abstract}

in the neuroprotection mediated by group-II mGlu receptors, we exposed pure cultures of cortical astrocytes to DCG-IV, 4C3HPG, or L-CCG-I for $10 \mathrm{~min}$. The astrocyte medium collected 2-20 hr after the exposure to any of these drugs was highly neuroprotective when transferred to mixed cultures treated with NMDA. This protective activity was reduced when $\mathrm{CHX}$ was applied to astrocyte cultures immediately after the transient exposure to group-II mGlu receptor agonists. We conclude that neuroprotection mediated by group-II mGlu receptors in cultured cortical cells requires new protein synthesis and involves an interaction between neurons and astrocytes.

Key words: cortical cultures; metabotropic glutamate receptors; excitotoxicity; astrocytes; neuroprotection; new protein synthesis
Metabotropic glutamate (mGlu) receptors form a family of eight subtypes, which have tentatively been classified into three groups (for review, see Pin and Duvoisin, 1995). Group-I mGlu receptors include mGlu1 and -5 , which are coupled to polyphosphoinositide hydrolysis when expressed in recombinant cells. Group-II (mGlu2 and -3) and group-III (mGlu4, -6, -7, and -8) mGlu receptor subtypes are negatively linked to adenylyl cyclase, although at least mGlu2 is also negatively coupled to voltage-sensitive $\mathrm{Ca}^{2+}$ channels (Ikeda et al., 1995). mGlu2, -4, and -7 have been found to be preferentially localized in presynaptic terminals (Shigemoto et al., 1995, 1996), and their activation inhibits glutamate release (for review, see Pin and Duvoisin, 1995). mGlu3 receptors are also expressed by astrocytes (Tanabe et al., 1993; Petralia et al., 1996), and their functional role is unknown.

Pharmacological activation of group-II or -III mGlu receptors protects neurons against excitotoxic degeneration (Bruno et al., 1994, 1995; Buisson and Choi, 1994, 1995; Altemus et al., 1995; Maiese et al., 1995; Orlando et al., 1995; Turetsky et al., 1995; Buisson et al., 1996). Because activation of group-II and -III mGlu receptors is expected to attenuate neuronal degeneration without hampering the efficiency of fast excitatory synaptic transmission, these receptors become potential targets for the experimental therapy of acute and chronic neurodegenerative disorders (for review, see Nicoletti et al.,

Received Aug. 13, 1996; revised Dec. 5, 1996; accepted Dec. 11, 1996.

Correspondence should be addressed to Dr. Ferdinando Nicoletti, Institute of Pharmacology, School of Pharmacy, University of Catania, Viale A. Doria 6, 95125 Catania, Italy.

Copyright (C) 1996 Society for Neuroscience $\quad 0270-6474 / 96 / 171891-07 \$ 05.00 / 0$
1996). It has been suggested that group-I or -III mGlu receptor agonists protect cultured neurons against NMDA toxicity by inhibiting the release of glutamate (Bruno et al., 1995) that occurs after the NMDA pulse and contributes to the maturation of the excitotoxic damage (Monyer et al., 1992; for review, see Choi, 1992). The existence of an additional mechanism, however, is suggested by the protective activity of the group-II mGlu receptor agonist (2S, $\left.1^{\prime} \mathrm{R}, 2^{\prime} \mathrm{R}, 3^{\prime} \mathrm{R}\right)$-2-(2,3-dicarboxycyclopropyl)glycine (DCGIV), under conditions in which there is no excitotoxic component in the neurodegenerative process (Nicoletti et al., 1996). We now report that the neuroprotective activity of group-II mGlu receptor agonists in mixed cultures of cortical cells requires new protein synthesis and involves the interaction between neurons and astrocytes.

\section{MATERIALS AND METHODS}

Mixed cortical culture. Mixed cortical cell cultures containing both neurons and astrocytes were prepared from fetal mice at $14-16 \mathrm{~d}$ of gestation, as described previously (Rose et al., 1992). Briefly, dissociated cortical cells were plated in $15 \mathrm{~mm}$ multiwell vessels (Falcon Primaria, Lincoln Park, NJ) on a layer of confluent astrocytes (7-14 d in vitro), using a plating medium of MEM-Eagle's salts (supplied glutamine-free) supplemented with $5 \%$ heat-inactivated horse serum, $5 \%$ fetal bovine serum, glutamine ( $2 \mathrm{~mm}$ ), and glucose (final concentration $21 \mathrm{~mm}$ ). Cultures were kept at $37^{\circ} \mathrm{C}$ in a humidified $5 \% \mathrm{CO}_{2}$ atmosphere. After 3-5 $\mathrm{d}$ in vitro, non-neuronal cell division was halted by 1-3 d exposure to $10 \mu \mathrm{M}$ cytosine arabinoside, and cultures were shifted to a maintenance medium identical to plating medium but lacking fetal serum. Subsequent partial medium replacement was carried out twice a week. Only mature cultures (13-14 d in vitro) were used for the experiments. 
Table 1. Neuroprotective activity of mGlu receptor agonists against NMDA toxicity in mixed cultures of cortical cells

\begin{tabular}{llllll} 
& \multicolumn{2}{c}{ Count of dead cells } & & \multicolumn{2}{c}{ LDH release } \\
\cline { 2 - 3 } \cline { 5 - 6 } & Control & $\begin{array}{l}\text { NMDA } \\
(100 \mu \mathrm{M})\end{array}$ & & Control & $\begin{array}{l}\text { NMDA } \\
(100 \mu \mathrm{M})\end{array}$ \\
\hline Basal & $36 \pm 6$ & $415 \pm 15$ & & $21 \pm 6$ & $245 \pm 9$ \\
DCG-IV, $1 \mu \mathrm{M}$ & $29 \pm 8$ & $163 \pm 6^{*}$ & & $31 \pm 5$ & $100 \pm 6^{*}$ \\
4C3HPG, $50 \mu \mathrm{M}$ & $42 \pm 12$ & $205 \pm 7^{*}$ & & $19 \pm 7$ & $120 \pm 5^{*}$ \\
PCCG-IV, $20 \mu \mathrm{M}$ & $28 \pm 4$ & $385 \pm 22$ & & $17 \pm 9$ & $261 \pm 10$ \\
DCG-IV + PCCG-IV & $31 \pm 6$ & $395 \pm 10$ & & $24 \pm 11$ & $240 \pm 8$ \\
4C3HPG + PCCG-IV & $31 \pm 5$ & $380 \pm 7$ & & $17 \pm 5$ & $210 \pm 8$ \\
L-CCG-I, 10 $\mu \mathrm{M}$ & $40 \pm 6$ & $197 \pm 8^{*}$ & & $15 \pm 7$ & $115 \pm 7^{*}$ \\
L-AP4, 10 $\mu \mathrm{M}$ & $26 \pm 4$ & $223 \pm 5^{*}$ & & $17 \pm 8$ & $137 \pm 6^{*}$
\end{tabular}

mGlu receptor agonists and/or PCCG-IV were applied in combination with NMDA. Values are means \pm SEM of $6-15$ determinations. ${ }^{*} p<0.01$ (one-way ANOVA + Fisher protected least significant difference), when compared with NMDA alone. Dead cells were counted as cells stained with trypan blue in three random fields/well (200 cells counted per field). LDH release is expressed as $\mathrm{mOD} / \mathrm{min}$. LDH, lactate dehydrogenase.

Glial cell culture. Glial cell cultures were prepared as described previously (Rose et al., 1992) from postnatal mice (1-3 d after birth). Dissociated cortical cells were grown in $15 \mathrm{~mm}$ multiwell vessels (Falcon Primaria) using a plating medium of MEM-Eagle's salts supplemented with $10 \%$ heat-inactivated horse serum, $10 \%$ fetal bovine serum, glutamine $(2 \mathrm{~mm})$, and glucose (final concentration $21 \mathrm{~mm}$ ). Cultures were kept at $37^{\circ} \mathrm{C}$ in a humidified $\mathrm{CO}_{2}$ atmosphere until they reached confluence (7-14 $\mathrm{d}$ in vitro). Confluent cultures were then used for the experiments or as a support for mixed cultures.

Exposure to excitatory amino acids. Brief exposure to NMDA (10 min), in the presence or absence of mGlu receptor agonists and/or antagonists or protein synthesis inhibitors, was carried out in mixed or pure cortical cultures at room temperature in a HEPES-buffered salt solution containing (in mM): $120 \mathrm{NaCl}, 5.4 \mathrm{KCl}, 0.8 \mathrm{MgCl}_{2}, 1.8 \mathrm{CaCl}_{2}, 20$ HEPES, 15 glucose. After $10 \mathrm{~min}$ the drugs were washed out, and cultures were incubated at $37^{\circ} \mathrm{C}$ for the following $24 \mathrm{hr}$ in medium stock (MS) (MEMEagle's supplemented with $15.8 \mathrm{mM} \mathrm{NaHCO}$ and glucose $<25 \mathrm{~mm}$ ). In some experiments, mixed cortical cultures were exposed for $10 \mathrm{~min}$ to mGlu receptor agonists, $6 \mathrm{hr}$ before the NMDA pulse. In another set of experiments, a glial-conditioned medium (GCM) was added to the cultures immediately after the NMDA pulse and was kept for the following $24 \mathrm{hr}$ of incubation. GCM was prepared as follows: glial cortical cultures were exposed for $10 \mathrm{~min}$ to $\mathrm{mGlu}$ receptor agonists, and then the drugs were washed out and cultures were kept in MS at $37^{\circ} \mathrm{C}$ for the following $20 \mathrm{hr}$. After this incubation, the medium was collected and used immediately for the experiments.

Assessment of neuronal injury. Neuronal injury was estimated in all experiments by examination of cultures with phase-contrast microscopy at $100-400 \times, 1 \mathrm{~d}$ after the insult, when the process of cell death was largely complete. Neuronal damage was quantitatively assessed in all experiments by estimation of dead neurons by trypan-blue staining. Stained neurons were counted from three random fields per well. Neuronal injury was also assessed by measuring the activity of lactate dehydrogenase $(\mathrm{LDH})$ released from damaged or destroyed cells into the extracellular medium $1 \mathrm{~d}$ after the addition of the excitotoxins. Because results obtained with cell count or measurement of LDH activity were similar, only the former method was used in most of the experiments.

Characterization of mGlu2/3 antibodies, immunocytochemistry, and Western blot analysis. Mixed cortical cultures at 13-14 d in vitro were stained for mGlu2/3 receptors using immunopurified polyclonal antibodies raised against a synthetic peptide corresponding to the following $\mathrm{C}$-terminal amino acid sequence of rat mGlu2 receptor (one-code letter): VPTVCNGREVVDSTTSSL (for a detailed description of the preparation of the antibody, see Koulen et al., 1996). The specificity of the antibody was assessed in HEK 293 cells transfected with mGlu2 or -3 subtype. In brief, HEK 293 cells were transfected with $4 \mu \mathrm{g}$ of plasmid DNA/dish by calcium phosphate precipitation (Chen and Okayama, 1987). Forty-eight hours later, cells were lysed, separated on $8 \%$ SDSPAGE, transferred to nitrocellulose membranes, and incubated with primary and secondary antibodies. The primary antibody was diluted

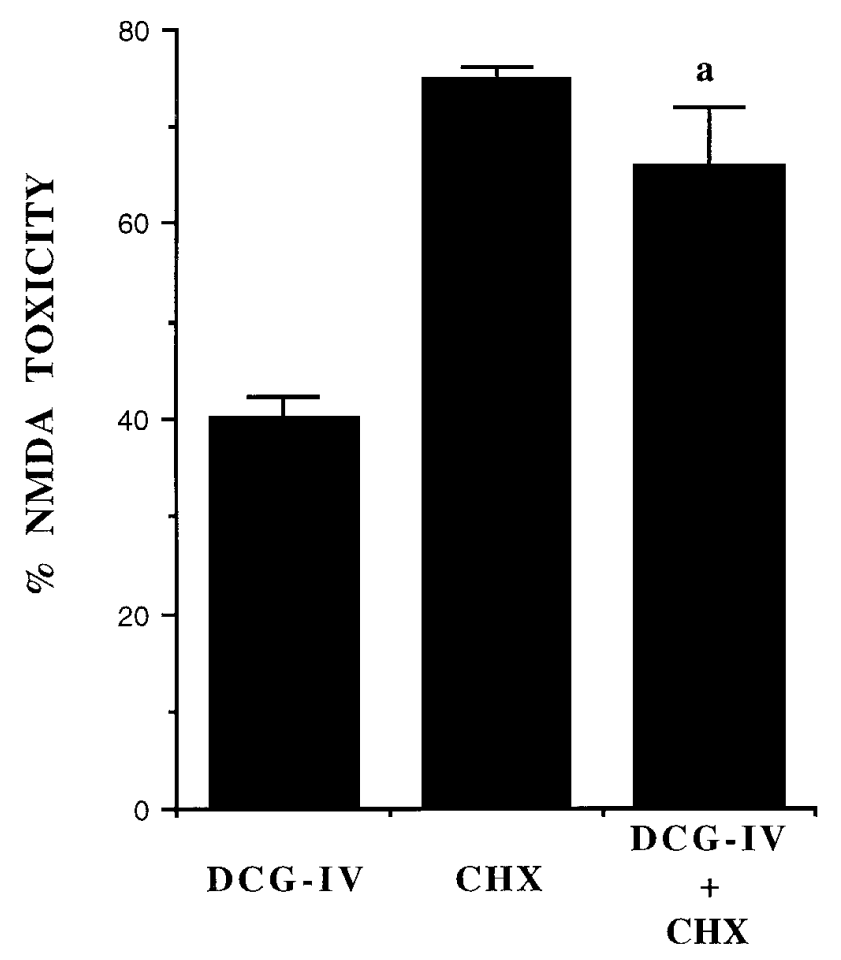

Figure 1. The protein synthesis inhibitor cycloheximide $(\mathrm{CHX})$ attenuates the neuroprotective activity of DCG-IV in mixed cultures of cortical cells. Cultures were exposed to a toxic pulse with $100 \mu \mathrm{M}$ NMDA in the absence or presence of DCG-IV. CHX (500 ng/ml) was applied to the cultures immediately after the NMDA pulse. Addition of $100 \mu \mathrm{M}$ NMDA resulted in the necrotic death of $70 \pm 8 \%$ of the neuronal population $(n=$ 32 ), without any apparent damage to the underlying monolayer of astrocytes. This value was set at $100 \%$. In untreated cultures, the number of trypan-blue-positive dead neurons was always $<3 \%$ of the total population. Values indicate the mean \pm SEM and were calculated from four independent experiments ( $n=4$ individual wells for each experiment). In each experiment, $\mathrm{SD}$ was $<10 \%$ of the mean value.

1:1000 in NETG buffer, and the secondary antibody (peroxidase-coupled goat anti-rabbit; Bio-Rad, Richmond, CA) was diluted 1:1500. Specific bands were detected using the enhanced chemiluminescence (ECL) Western blotting analysis system (Amersham, Milano, Italy).

For immunostaining, mixed cortical cells were washed twice with PBS, fixed for $30 \mathrm{~min}$ in $2 \%$ paraformaldehyde, washed three times with PBS, and then permeabilized with $0.1 \%$ Triton X-100 in PBS for 10 min. Cells were then washed, blocked with serum, and incubated with the primary antibody (1:2000) for $2 \mathrm{hr}$ at room temperature. After the cells were washed three times, the secondary antibody was added for $1 \mathrm{hr}$. After the reaction with avidin-biotin-horseradish peroxidase (Vectastain, ABCElite kit, Vector Labs, Burlingame, CA), staining was developed by exposure to $0.05 \%$ diaminobenzidine $/ 0.01 \% \mathrm{H}_{2} \mathrm{O}_{2}(2-10 \mathrm{~min})$. Western blot analysis in protein extracts from pure cultures of mouse cortical astrocytes was performed as described by Casabona et al. (1996), using dilutions of the primary antibody up to 1:250. Protein extracts from (1) rat cerebral cortex, (2) mouse cerebral cortex, and (3) pure cultures of rat cortical astrocytes, prepared as described previously (Condorelli et al., 1989), were used as controls. Immunoreactive bands were detected by ECL (see above).

Materials. NMDA, L-2-amino-4-phosphonobutanoate (L-AP4), S-4carboxy-3-hydroxyphenylglycine (4C3HPG), (2S,1'S,2'S)-2-(carboxycyclopropyl)glycine (L-CCG-I), and 3,5-dihydroxyphenylglycine (DHPG) were purchased from Tocris Cookson (Bristol, UK).Cycloheximide (CHX) was obtained from Sigma (St. Louis, MO). DCG-IV was a kind gift of Professor H. Shinozaki (Tokyo Metropolitan Institute for Medical Sciences, Japan) and $\left(2 \mathrm{~S}, 1^{\prime} \mathrm{S}, 2^{\prime} \mathrm{S}, 3^{\prime} \mathrm{R}\right)-2-\left(2^{\prime}\right.$ carboxy-3'-phenylcyclopropyl)glycine (PCCG-IV) was kindly provided by Professor R. Pelliccari (Institute of Pharmacology and Chemistry, University of Perugia, Italy). 


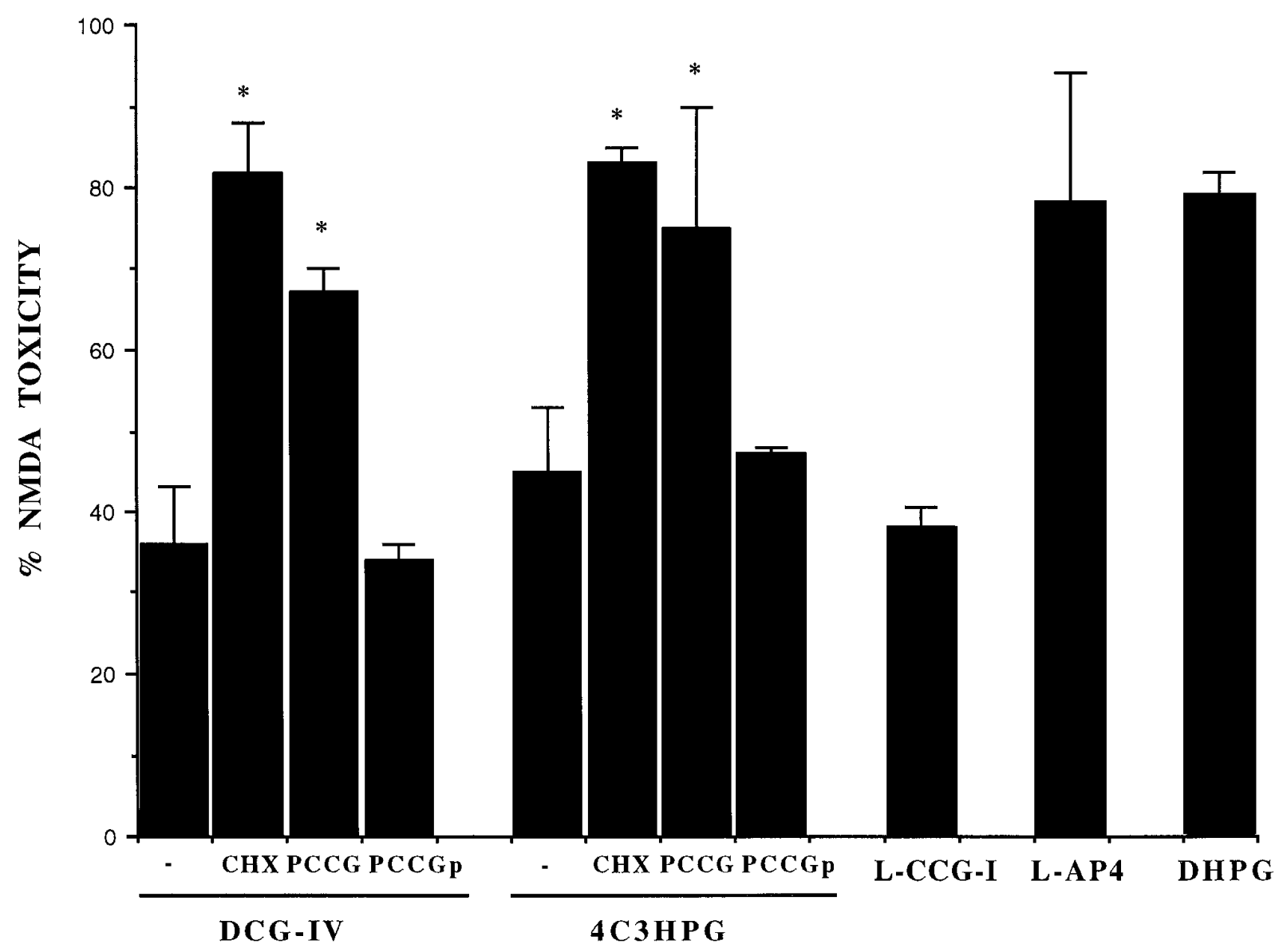

Figure 2. Neuroprotective activity of group-II mGlu receptor agonists applied to mixed cultures for $10 \mathrm{~min}, 6 \mathrm{hr}$ before the toxic pulse with NMDA. DCG-IV, $1 \mu \mathrm{M}$; 4C3HPG, $50 \mu \mathrm{M}$; L-CCG-I, $10 \mu \mathrm{M}$; L-AP4, $10 \mu \mathrm{M}$; DHPG, $50 \mu \mathrm{M}$; PCCG-IV, $20 \mu \mathrm{M}$; CHX, 500 ng/ml. CHX was applied immediately after the transient exposure to DCG-IV or 4C3HPG and was maintained during the $6 \mathrm{hr}$ interval preceding the NMDA pulse. PCCG-IV was applied either in combination with DCG-IV or 4C3HPG (labeled as PCCG) or immediately after the exposure to DCG-IV or 4C3HPG (labeled as PCCGp). In the latter case, PCCG-IV was maintained during the $6 \mathrm{hr}$ interval preceding the NMDA pulse (labeled as PCCGp). Values (mean \pm SEM) were calculated from three to six independent experiments ( $n=4$ individual wells in each experiment). ${ }^{*} p<0.01$ [one-way ANOVA + Fisher protected least significant difference (PLSD)] when compared with values obtained with DCG-IV or 4C3HPG without addition of CHX or PCCG-IV. Neuroprotection by DCG-IV or 4C3HPG was also significant when both drugs were transiently applied 12 or $20 \mathrm{hr}$ before the NMDA pulse (not shown).

\section{RESULTS}

In primary cultures of mouse cortical cells, a 10 min pulse with 100 $\mu \mathrm{M}$ NMDA induced necrotic death of $\sim 70 \%$ of the neuronal population, without damaging the underlying monolayer of astrocytes. As expected, the selective group-II mGlu receptor agonists DCG-IV and 4C3HPG, as well as the preferential group-II mGluR agonist L-CCG-I, substantially reduced neuronal toxicity when applied in combination with NMDA. This neuroprotection was prevented by the putative group-II mGlu receptor antagonist PCCG-IV (Thomsen et al., 1996) (Table 1). To unravel the possible role of a genetic program in the neuroprotective activity of group-II mGlu receptor agonists, we used the protein synthesis inhibitor $\mathrm{CHX}$. CHX inhibited ${ }^{3} \mathrm{H}$-glycine incorporation into proteins in a concentration-dependent fashion, with an apparent $\mathrm{IC}_{50}$ value of $100 \mathrm{ng} / \mathrm{ml}$. CHX was used routinely at a concentration of $500 \mathrm{ng} / \mathrm{ml}$. When applied immediately after the NMDA pulse, CHX was inactive per se, but it attenuated the neuroprotective activity of DCG-IV (Fig. 1). This suggested that neuroprotection was mediated by new protein synthesis, which was induced during the 10 min exposure to DCG-IV. To examine this point further, we transiently applied DCG-IV, 4C3HPG, or L-CCG-I 6-20 hr before a toxic pulse with NMDA. All of these group-II mGlu receptor agonists attenuated NMDA toxicity to the same extent as they were co-added with NMDA (exemplified in Fig. 2). This neuroprotective activity was prevented by $\mathrm{CHX}$ (when present during the 6-20 hr interval) as well as by PCCG-IV, which was active, however, when present during but not after the transient exposure to DCG-IV or 4C3HPG (Fig. 2). A 10 min preincubation with the group-III mGlu receptor agonist L-AP4 or the group-I mGlu receptor agonist DHPG did not substantially protect against NMDA toxicity (Fig. 2), although L-AP4 was neuroprotective when applied in combination with NMDA (Table 1).

Because the mGlu3 receptor is present in astrocytes (Tanabe et al., 1993; Petralia et al., 1996), we wondered whether astrocytes contribute to the neuroprotective activity of group-II mGlu receptor agonists. To examine this question, we incubated pure cultures of mouse cortical astrocytes with DCG-IV, 4C3HPG, or L-CCG-I for $10 \mathrm{~min}$ and collected the medium at different times after this incubation. The astrocyte medium collected 2-20 hr after the exposure to group-II mGlu receptor agonists was highly neuroprotective when transferred to sister mixed cultures treated with NMDA (Figs. 3, 4). In contrast, the medium collected from untreated astrocyte cultures or from cultures treated with L-AP4 or DHPG was inactive (Fig. 4). The conditioned medium removed 
Figure 3. Neuroprotective activity of the glial-conditioned medium collected from pure cultures of astrocytes, at different times after a $10 \mathrm{~min}$ exposure to DCG-IV $(1 \mu \mathrm{M})$. Values were obtained from a representative experiment and calculated from the mean of four individual determinations. Values relative to the glial-conditioned medium collected at 2, 6 , or $20 \mathrm{hr}$ after exposure to DCG-IV were significantly different as compared with values obtained with control (CTRL) astrocyte medium (i.e., with medium from astrocytes treated with the buffer alone) or with the medium collected from astrocyte cultures immediately after washing out DCG-IV (labeled as 0$)(p<0.01$ by one-way ANOVA + Fisher PLSD test). This experiment was repeated two times with similar results.

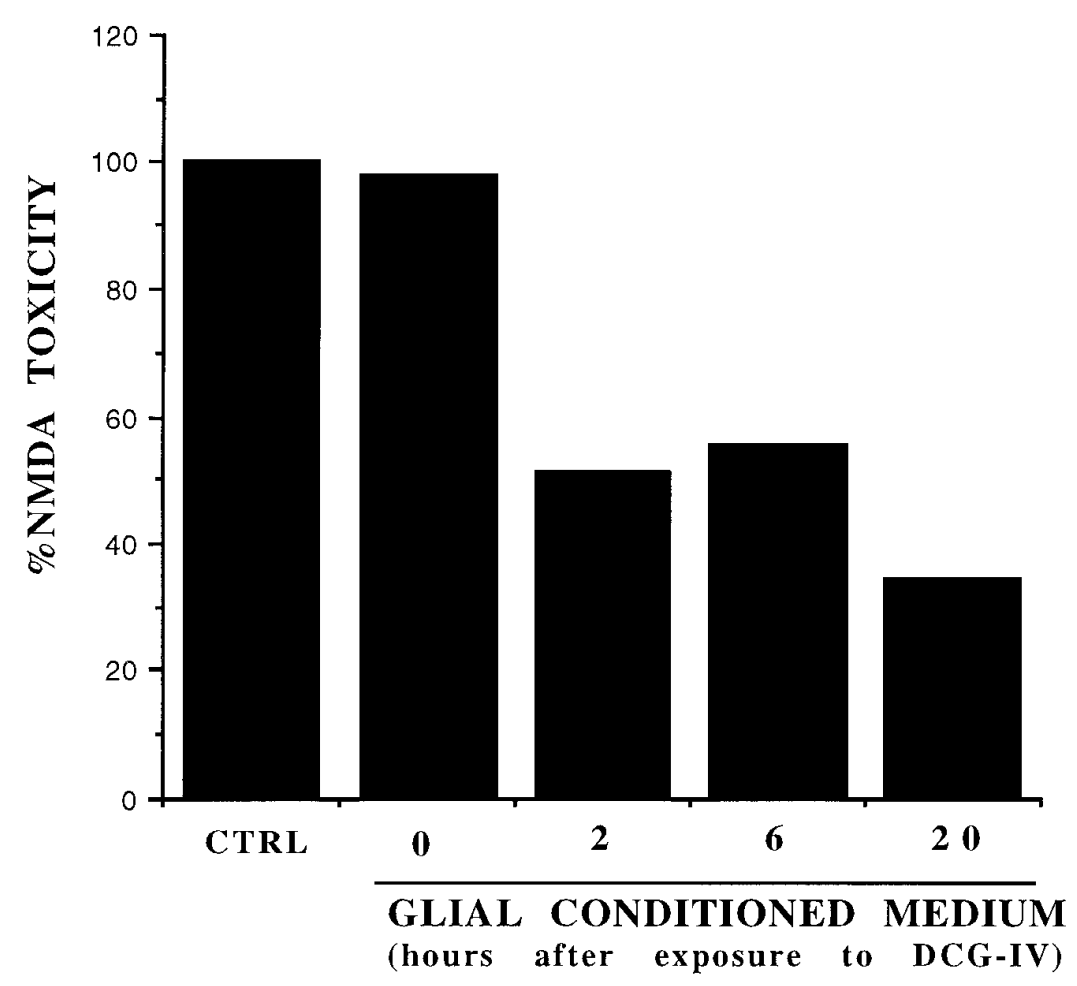

Figure 4. Neuroprotective activity of the conditioned medium collected from pure cultures of astrocytes $20 \mathrm{hr}$ after a $10 \mathrm{~min}$ exposure to the indicated mGlu receptor agonists. CTRL, Control medium (i.e., medium collected from astrocyte cultures treated with the buffer alone). DCG-IV, 1 $\mu \mathrm{M} ; 4 C 3 H P G, 50 \mu \mathrm{M} ; L-C C G-I, 10 \mu \mathrm{M}$; $L-A P 4,10 \mu \mathrm{M} ; D H P G, 50 \mu \mathrm{M}$. Values (mean \pm SEM) were calculated from three to five independent experiments $(n=4$ individual wells in each experiment). ${ }^{*} p<0.01$ (one-way ANOVA + Fisher PLSD) when compared with CTRL.

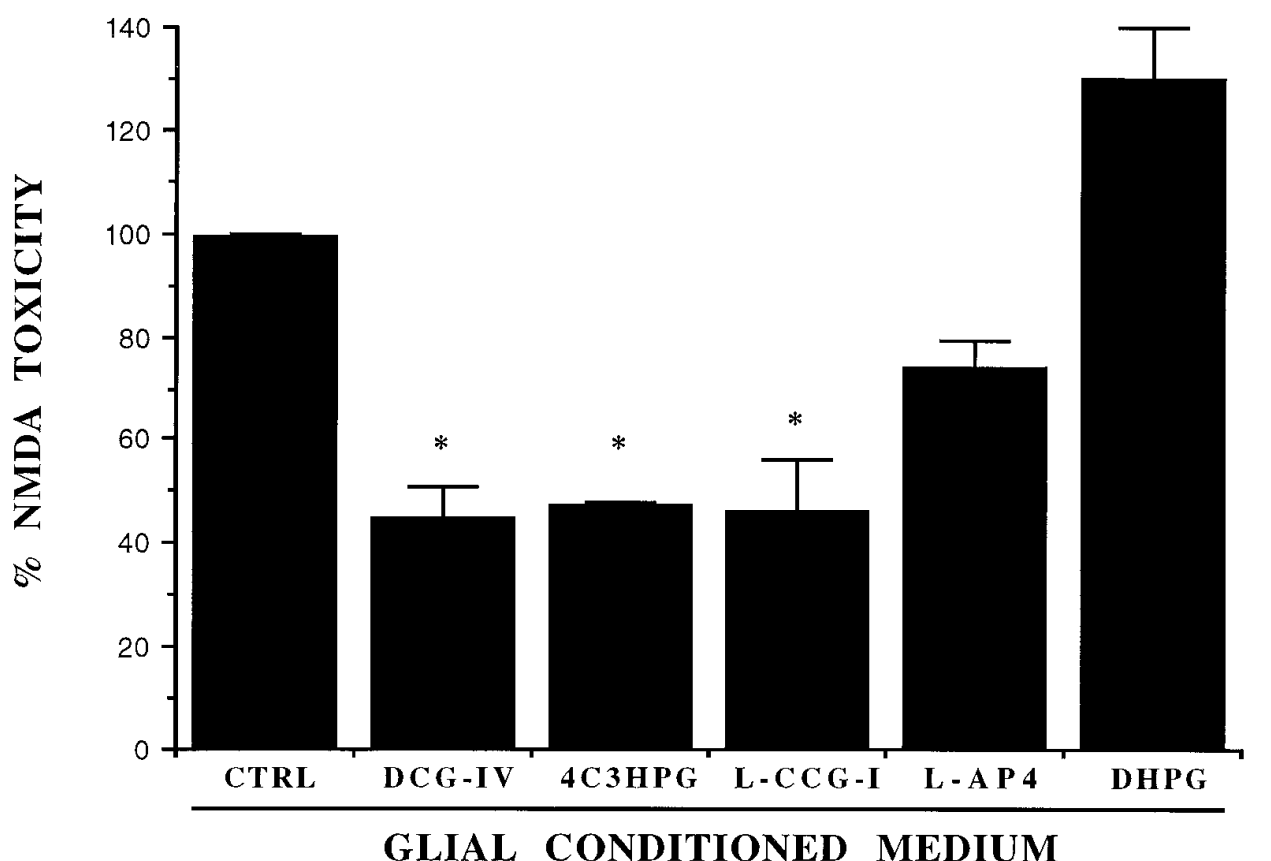

To confirm the presence of group-II mGlu receptors in astrocytes, we performed immunocytochemical studies in mixed cultures using a polyclonal antibody generated against a C-terminal amino acid sequence that is highly homologous between mGlu2 and -3 receptors, This antibody specifically labeled protein extracts from HEK 293 cells transfected with either mGlu2 or mGlu3 receptor cDNAs (Fig. $6 A$ ) and stained both neurons and the underlying monolayer of astrocytes in mixed cultures of mouse cortical cells (Fig. 6B). Western blot analysis, however, did not reveal any immunoreactive band in protein extracts from pure mouse cortical astrocyte cultures, under conditions in which the 


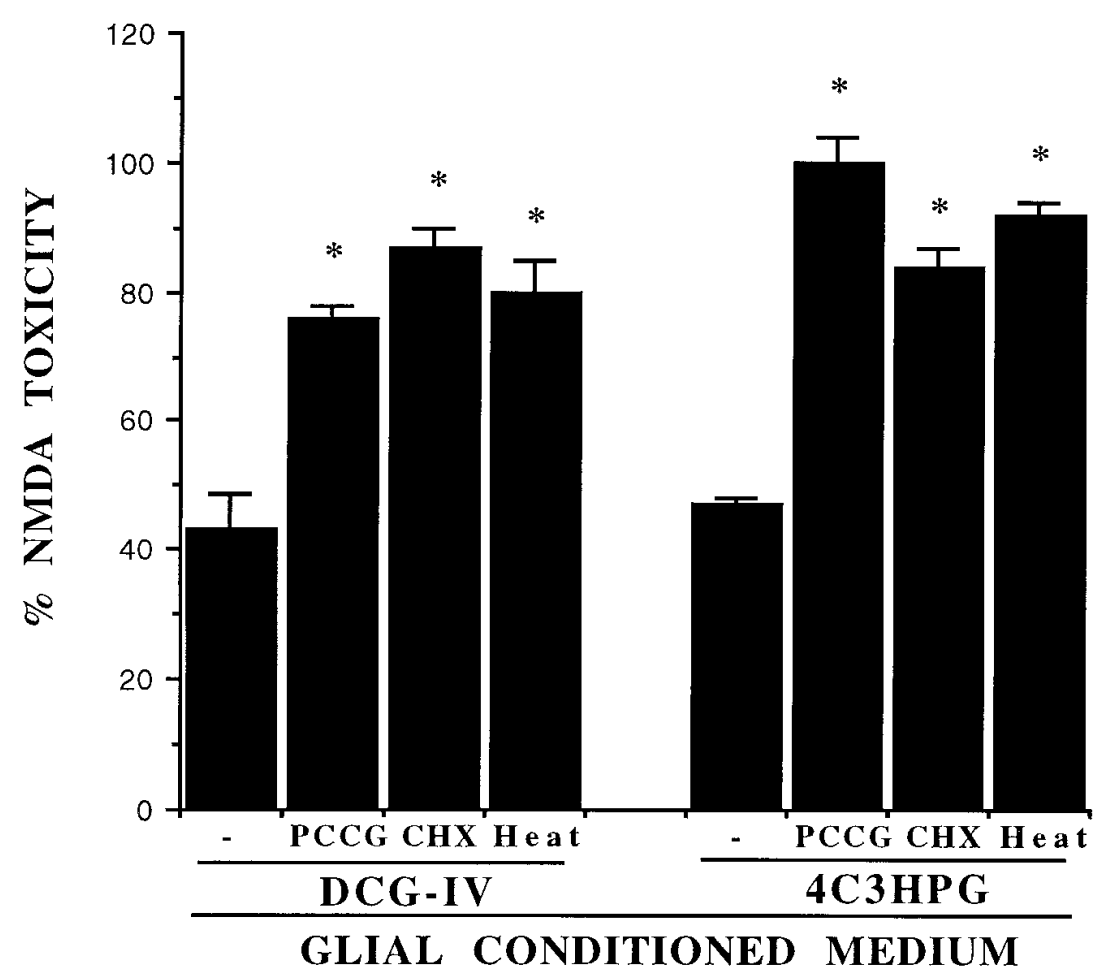

Figure 5. The neuroprotective activity of the glialconditioned medium collected from pure cultures of astrocytes transiently exposed to DCG-IV $\left(\begin{array}{lll}1 & \mu \mathrm{M}) & \text { or }\end{array}\right.$ 4C3HPG $(50 \mu \mathrm{M})$ is attenuated under the following conditions: (1) when PCCG-IV $(P C C G, 20 \mu \mathrm{M})$ is present during the exposure to $D C G-I V$ or $4 C 3 H P G$; (2) when CHX $(500 \mathrm{ng} / \mathrm{ml})$ is applied to cultured astrocytes immediately after the exposure to DCG-IV or 4C3HPG and maintained afterward; or (3) when the medium of astrocytes treated with DCG-IV or 4C3HPG is exposed to $100^{\circ} \mathrm{C}$ for $20 \mathrm{~min}$ (Heat) just before being transferred to mixed cortical cultures. Values are mean \pm SEM and were calculated from three to five independent experiments ( $n=4$ individual wells in each experiment). ${ }^{*} p<0.01$ when compared with the glial-conditioned medium collected from astrocytes treated with DCG-IV or 4C3HPG alone.
mGlu2/3 receptor antibody labeled extracts from both rat and mouse cerebral cortex (not shown; for additional details, see legend of Fig. 6). One possible explanation is that the amount of mGlu3 receptor protein expressed by cultured astrocytes is below the detection level by Western blot analysis. Accordingly, no immunoreactive band was found in extracts from cultures of rat cortical astrocytes, where mGlu3 receptor mRNA levels were detectable by RT-PCR (our unpublished observation).

\section{DISCUSSION}

mGlu receptors have recently been considered as a putative target for the experimental therapy of neurodegenerative disorders, because their activation affects multiple intracellular events that contribute not only to the induction but also to the progression of neuronal damage (for review, see Nicoletti et al., 1996). Activation of group-II mGlu receptors protects cultured neurons against degeneration induced by various insults, including excitotoxins (Bruno et al., 1994, 1995; Buisson and Choi, 1995; Buisson et al., 1996), oxygen-glucose deprivation (Buisson and Choi, 1995), $\beta$-amyloid peptide (Copani et al., 1995), and the broad protein kinase inhibitor staurosporine (Koh et al., 1995). In addition, intracerebral infusion of group-II mGlu receptor agonists protects against quinolinic acid-induced lesions of striatal medium-size spiny neurons (Altemus et al., 1995; Orlando et al., 1995), as well as against hippocampal neuronal degeneration secondary to kainate-induced seizures (Kwak et al., 1994). The neuroprotective activity of group-II mGlu receptor agonists is generally ascribed to the activation of neuronal mGlu2 receptors, which are presynaptically located and inhibit glutamate release (for review, see Pin and Duvoisin, 1995). Inhibition of glutamate release, however, cannot account for the neuroprotective activity of group-II mGlu receptor agonists against apoptosis induced by oxygen-glucose deprivation (Buisson and Choi, 1994), $\beta$-amyloid peptide (Copani et al., 1995), or staurosporine (Koh et al., 1995), because apoptosis by oxygen-glucose deprivation or $\beta$-amyloid peptide was in- duced in the presence of ionotropic glutamate receptor antagonists, whereas staurosporine inhibits both protein kinase $\mathrm{C}$ or $\mathrm{Ca}^{2+} /$ calmodulin-dependent protein kinase II (Ruegg and Burgess, 1989), which have been implicated in the development of excitotoxic damage (Favaron et al., 1990; Dawson et al., 1995). In addition, DCG-IV protects cultured neurons even when applied 30 min after a toxic pulse with NMDA, when large amounts of endogenous glutamate have already accumulated in the extracellular medium (Bruno et al., 1995).

This suggests that activation of group-II mGlu receptors promotes a mechanism of neuronal rescue, which cannot be simply reconducted to the inhibition of glutamate release. Accordingly, we have found that neuroprotection mediated by group-II mGlu receptor activation is long lasting (because DCG-IV, 4C3HPG, or L-CCG-I were still active when transiently applied hours before the NMDA pulse) and requires new protein synthesis. In contrast, the group-III mGlu receptor agonist L-AP4 lost its neuroprotective activity when applied before the NMDA pulse. Group-II and -III mGlu receptors share the same transduction pathway (Tanabe et al., 1992, 1993) but show a different anatomical localization. mGlu7 receptors, for example, are localized in presynaptic membrane specialization, whereas group-II mGlu receptors are found predominantly in preterminal axons (Shigemoto et al., 1995, 1996). In addition, mGlu3 receptors are found in glial cells (Tanabe et al., 1993; Petralia et al., 1996), whereas evidence for the presence of group-III mGlu receptors in astrocytes is lacking. A role for astrocytes in neuroprotection was suggested by the evidence that cortical neurons in pure cultures are more sensitive to toxicity induced by acute exposure to glutamate, by $24 \mathrm{hr}$ exposure to NMDA, or by oxygen-glucose deprivation (Dugan et al., 1995), and less sensitive to the protective activity of DCG-IV against kainate-induced degeneration (our unpublished observation) than neurons in mixed cultures. We have hypothesized therefore either that astrocytes produce a permissive factor that 
A

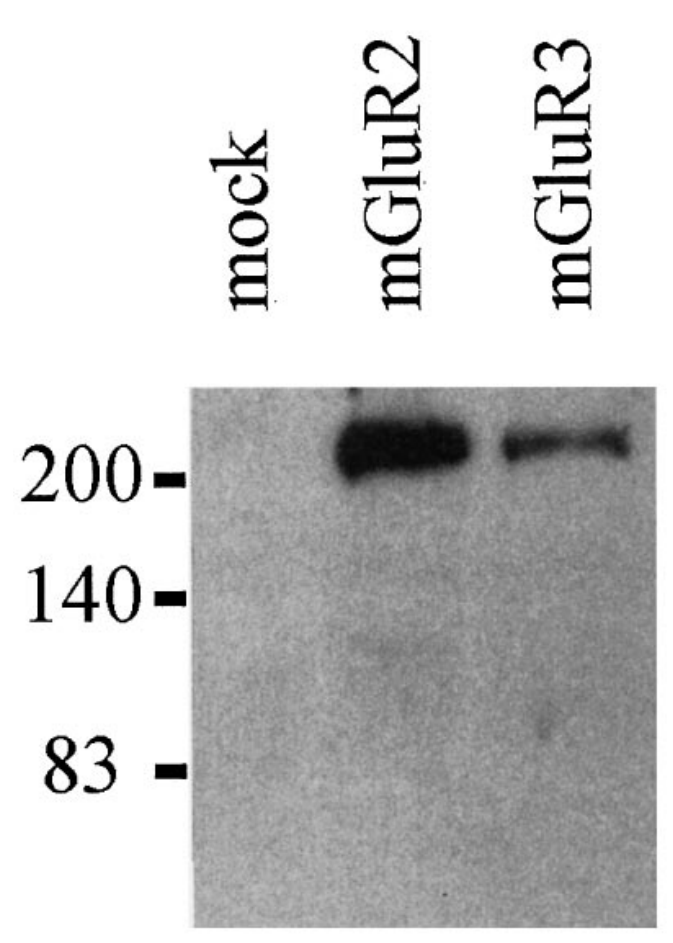

B
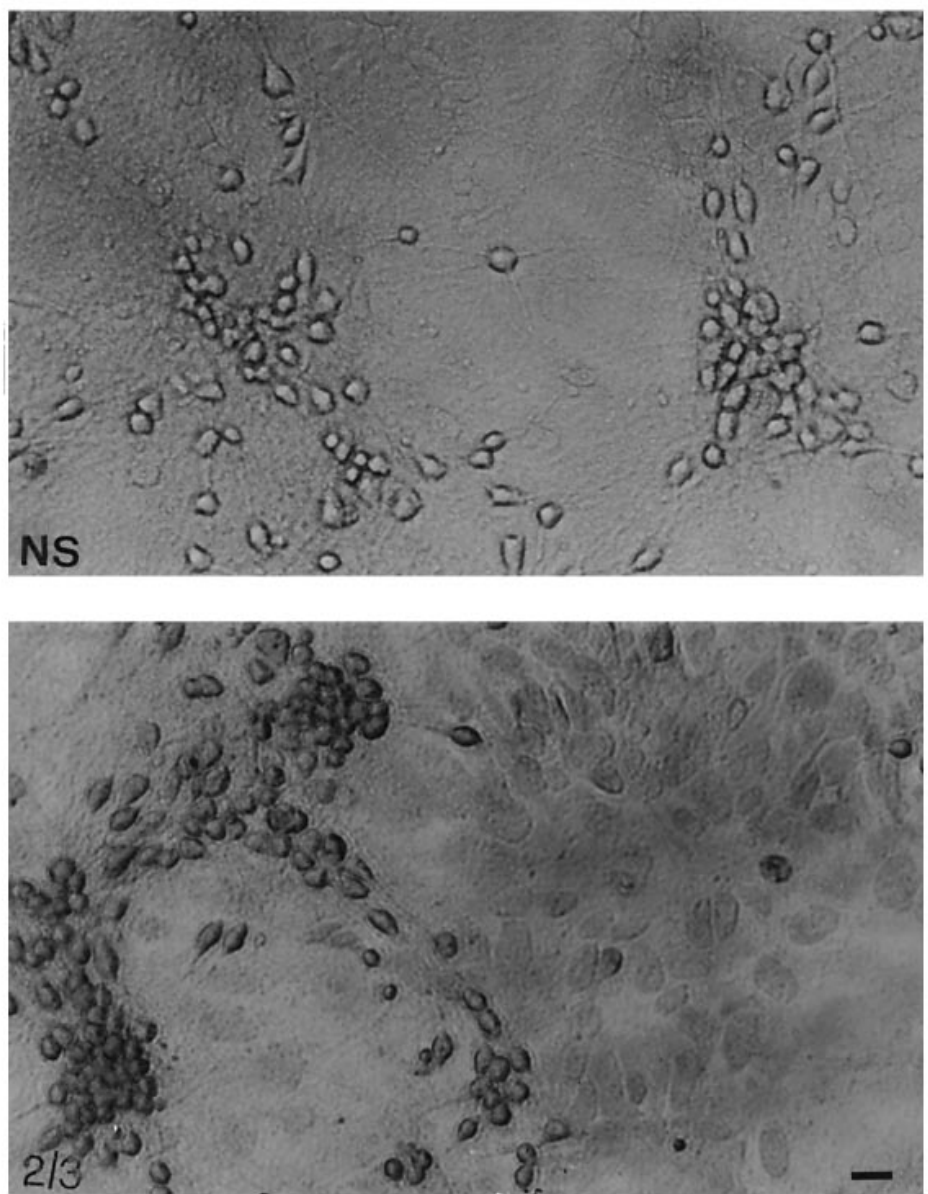

Figure 6. A, Immunoblotting with purified mGluR2/3 antibodies on lysates from HEK 293 cells transfected with a plasmid encoding the mGlu2 or -3 receptor. Note that the antibody reacts mostly with a high molecular weight band, which may correspond to receptor aggregates (Hayashi et al., 1993). A $100 \mathrm{kDa}$ band corresponding to the deduced molecular weight of mGlu2 and -3 receptors was detected only after long-term exposure. Untransfected HEK 293 cells (mock) or HEK 293 cells transfected with mGlu1a, -5a, and -4 receptor cDNA (not shown) were not stained by the mGlu2/3 receptor antibody. $B$. Immunostaining of mixed cultures of cortical cells with the mGlu2/3 receptor antibody. Note that both neurons and astrocytes are stained by the antibody. 2/3, Specific staining; $N S$, nonspecific staining. Scale bar, $20 \mu \mathrm{m}$. We also performed Western blot analysis on protein extracts from membranes prepared from (1) pure cultures of mouse astrocytes, (2) pure cultures of rat astrocytes, (3) mouse cerebral cortex, and (4) rat cerebral cortex (60 $\mu \mathrm{g}$ of protein loaded for each lane). In extracts from mouse or rat cerebral cortex, the mGlu2/3 receptor antibody labeled exclusively a $100 \mathrm{kDa}$ band and an additional band of higher molecular weight, which may correspond to receptor aggregates (not shown). No immunolabeling was observed in extracts from either mouse or rat cultured astrocytes. This suggests that the antibody that we have used is specific for $\mathrm{mGlu} 2 / 3$ but the amount of receptor(s) expressed by cultured astrocytes is possibly too low to be detected by Western blot analysis.

enables the protective activity of neuronal group-II mGlu receptors or that activation of group-II mGlu receptors in astrocytes promotes a form of glial-neuronal signaling responsible for neuroprotection. To examine this question, we transiently exposed cultures of pure astrocytes to mGlu receptor agonists and then transferred the conditioned medium to sister mixed cultures treated with NMDA. Only the glial-conditioned medium collected from astrocytes treated with group-II mGlu receptor agonists exhibited neuroprotective activity, which was prevented by PCCGIV, a selective group-II mGlu receptor antagonist (Thomsen et al., 1996). PCCG-IV, however, was not effective when applied to cultured astrocytes after the exposure to agonists, suggesting that neuroprotection did not result from the uptake and successive release of DCG-IV or 4C3HPG into the conditioned medium. It is possible that astrocytes synthesize and release a proteic neurotrophic factor, which is denaturated when samples are exposed to $100^{\circ} \mathrm{C}$ for $20 \mathrm{~min}$. Alternatively, activation of group-II mGlu receptors (presumably mGlu3) in astrocytes may induce the syn- thesis of an enzyme, which in turn catalyzes the formation of a heat-sensitive neurotrophic factor.

The mechanism by which activation of group-II mGlu receptors in astrocytes induces protein synthesis is unknown. In recombinant cells, these receptors are negatively linked to adenylyl cyclase (Tanabe et al., 1992, 1993). Under some circumstances, however, activation of native group-II mGlu receptors paradoxically may amplify an evoked increase in cAMP formation, perhaps because of the presence of particular isoforms of adenylyl cyclase that are stimulated by the large amounts of the $\beta \gamma$-subunits released from the $\mathrm{G}_{\mathrm{i}}$ proteins (Winder and Conn, 1993). Interestingly, the latter mechanism occurs in astrocytes and is involved in certain forms of glial-neuronal communication (Balazs et al., 1996; Winder et al., 1996). Alternatively, group-II mGlu receptor agonists might stimulate the mitogen-activated protein kinase pathway, as they do in neurons (Strasser and Choi, 1996). Either of these transduction pathways may induce the expression of genes encoding putative neuroprotective factors that are released from astrocytes and 
protect the neighbor neurons against excitotoxic death. A role for cAMP in the glial mechanism responsible for neuroprotection may help explain the intriguing finding that dibutyryl-cAMP, a membrane-permeable cAMP analog, is neuroprotective per se and may obliterate the protective activity of DCG-IV against NMDA toxicity in mixed cultures of cortical cells (Mattson and Kater, 1988; Bruno et al., 1995).

In conclusion, the present results provide evidence for a novel form of glial-neuronal signaling that contributes to the neuroprotective activity of group-II mGlu receptor agonists in mixed cultures of cortical cells. Signaling seems to be mediated by an astrocyte-derived neurotrophic factor, the production of which requires new protein synthesis. This defensive mechanism, however, may not be efficient against all types of excitotoxic insults, because activation of group-II mGlu receptors does not protect cortical neurons grown in mixed cultures against AMPA toxicity (Bruno et al., 1995; Buisson and Choi, 1995; Buisson et al., 1996), whereas the effect on kainate-induced toxicity is still controversial. It is noteworthy that the presence of astrocytes exacerbates AMPA neurotoxicity, although it protects cultured neurons against glutamate or NMDA toxicity (Dugan et al., 1995).

\section{REFERENCES}

Altemus KL, Colwell CS, Levine MS (1995) Modulation of excitotoxic damage in the neostriatum by metabotropic glutamate receptors. Soc Neurosci Abstr 21:217.6.

Balazs R, Miller S, Romano C, de Vries A, Cotman CW (1996) Metabotropic glutamate receptors in cerebral cortical astrocytes: pharmacological properties of mGluR5 and interaction between PLC- and adenylate cyclase (AC)-coupled transduction systems. 2nd International Meeting on Metabotropic Glutamate Receptors. Neuropharmacology 35:A2.

Bruno V, Copani A, Battaglia G, Raffaele R, Shinozaki H, Nicoletti F (1994) Protective effect of the metabotropic glutamate receptor agonist, DCG-IV, against excitotoxic neuronal death. Eur J Pharmacol 256:109-112.

Bruno V, Battaglia G, Copani A, Giffard RG, Raciti G, Raffaele R, Shinozaki H, Nicoletti F (1995) Activation of class II or III metabotropic glutamate receptors protects cultured cortical neurons against excitotoxic degeneration. Eur J Neurosci 7:1906-1913.

Buisson A, Choi DW (1995) The inhibitory mGluR agonist, S-4-carboxy3-hydroxy-phenylglycine selectively attenuates NMDA neurotoxicity and oxygen-glucose deprivation-induced neuronal death. Neuropharmacology 34:1081-1087.

Buisson A, Yu S, Choi DW (1994) Role of metabotropic glutamate receptors in excitotoxic and apoptotic cell death. Soc Neurosci Abstr 20:198:5.

Buisson A, Yu SP, Choi DW (1996) DCG-IV selectively attenuates rapidly triggered NMDA-induced neurotoxicity in cortical neurons. Eur J Neurosci 8:138-143.

Casabona G, Knopfel T, Kuhn R, Gasparini F, Baumann P, Sortino MA, Copani A, Nicoletti F (1996) Expression and coupling to polyphosphoinositide hydrolysis of group-I metabotropic glutamate receptors in early postnatal and adult rat brain. Eur J Neurosci, in press.

Chen C, Okayama H (1987) High efficiency transformation of mammalian cells by plasmid DNA. Mol Biol Cell 7:2745-2761.

Choi DW (1992) Excitotoxic cell death. J Neurobiol 23:1261-1276.

Condorelli DF, Kaczmarek L, Nicoletti F, Arcidiacono A, Dell'Albani P, Ingrao F, Magrì G, Malaguarnera L, Avola R, Messina A, Giuffrida Stella AM (1989) Induction of protooncogene fos by extracellular signals in primary glial cell cultures. J Neurosci Res 23:234-239.

Copani A, Bruno V, Battaglia G, Leanza G, Pellitteri R, Russo A, Stanzani S, Nicoletti F (1995) Activation of metabotropic glutamate receptors protects neurons against apoptosis induced by $\S$-amyloid peptide. Mol Pharmacol 47:890-897.

Dawson TM, Hung K, Dawson VL, Steyner JP, Snyder SH (1995) Neuroprotective effects of gangliosides may involve inhibition of nitric oxide synthase. Ann Neurol 37:115-118.

Dugan LL, Bruno VMG, Amagasu SM, Giffard RG (1995) Glia modulate the response of murine cortical neurons to excitotoxicity: glia exacerbate AMPA neurotoxicity. J Neurosci 15:4545-4555.

Favaron M, Manev H, Siman R (1990) Down regulation of protein kinase $\mathrm{C}$ protects cerebellar granule neurons in primary culture from glutamate-induced neuronal death. Proc Natl Acad Sci USA 87:1983-1987.

Hayashi Y, Momiyama A, Takahashi T, Ohishi H, Ogawa-Meguro R, Shigemoto R, Mizuno N, Nakanishi S (1993) Role of a metabotropic glutamate receptor in synaptic regulation in the accessory olfactory bulb. Nature 366:687-690.

Koulen P, Malitschek B, Kuhn R, Wassle H, Brandstatter JH (1996) Group II and group III metabotropic glutamate receptors in the rat retina: distributions and developmental expression patterns. Eur J Neurosci, in press.

Kwak S, Ishida M, Miyamoto M, Shinozaki H (1994) DCG-IV, a potent agonist for metabotropic glutamate receptors alleviate excitotoxininduced neuronal damage in vivo. Abstract of the Ninth Rinshoken International Conference on Excitatory Amino Acid Approaches to Clinical Use, November 28-30, p 16.

Maiese K, Greenberg R, Boccone L, Swiriduk M (1995) Activation of metabotropic glutamate receptor is neuroprotective during nitric oxide toxicity in primary hippocampal neurons of rats. Neurosci Lett 194:173-176.

Mattson MP, Kater SB (1988) Intracellular messenger in the generation and degeneration of hippocampal neuroarchitecture. J Neurosci Res 21:447-464.

Monyer H, Giffard RG, Hartley DM, Dugan LL, Goldberg MP, Choi DW (1992) Oxygen and glucose deprivation-induced neuronal injury in cortical cell cultures is reduced by tetanus toxin. Neuron 8:967-973.

Nicoletti F, Bruno V, Copani A, Casabona G, Knoepfel T (1996) Metabotropic glutamate receptors: a new target for the therapy of neurodegenerative disorders? Trends Neurosci 19:267-271.

Orlando LR, Standaert DG, Cha J-H, Penney JB, Young AB (1995) Metabotropic receptors in excitotoxicity: (S)-4C3HPG protects against striatal quinolinic acid lesions. Soc Neurosci Abstr 21:529.19.

Petralia RS, Wang W-X, Niedzielski AS, Wenthold RJ (1996) The metabotropic glutamate receptors, mGluR2 and mGluR3, show unique postsynaptic, presynaptic and glial localizations. Neuroscience 71:949-976.

Pin JP, Duvoisin R (1995) The metabotropic glutamate receptors: structure and functions. Neuropharmacology 34:1-26.

Rose K, Goldberg MP, Choi DW (1992) Cytotoxicity in murine neocortical cell culture. In: Methods in toxicology, vol 1, in vitro biological systems (Tyson CA, Frazier JM, eds), pp 46-60. San Diego: Academic.

Ruegg UT, Burgess GM (1989) Staurosporine, K-252 and UCN-01: potent but nonspecific inhibitors of protein kinases. Trends Pharmacol Sci 10:218-220.

Shigemoto R, Wada E, Ohishi H, Takada M, Mizuno M, Roberts JDB, Somogyi P (1995) Differential presynaptic localization of metabotropic glutamate receptor subtypes, mGluR2/3 and mGluR7 in the rat hippocampus. Soc Neurosci Abstr 21:338.20.

Shigemoto R, Kulik A, Roberts JDB, Ohishi H, Nusser Z, Kaneko T, Somogyi P (1996) Target-cell-specific concentration of a metabotropic glutamate receptor in the presynaptic active zone. Nature 381:523-525.

Strasser U, Choi DW (1996) Activation of ERK1/2 by agonists for metabotropic glutamate receptors in serum-deprived cortical neuronal cultures. 2nd International Meeting on Metabotropic Glutamate Receptors. Neuropharmacology 35:A30.

Tanabe Y, Masu M, Ishii I, Shigemoto R, Mizuno N, Nakanishi S (1992) A family of metabotropic receptors. Neuron 8:169-179.

Tanabe Y, Nomura A, Masu M, Shigemoto R, Mizuno N, Nakanishi S (1993) Signal transduction, pharmacological properties, and expression patterns of two rat metabotropic glutamate receptors, mGluR3 and mGluR4. J Neurosci 13:1372-1378.

Thomsen C, Bruno V, Nicoletti F, Marinozzi M, Pellicciari R (1996) (2S,1'S, 2'S , 3'R)-2-(2'-Carboxy-3'-phenylcyclopropyl)glycine, a potent and selective antagonist of type- 2 metabotropic glutamate receptors. Mol Pharmacol 50:6-9.

Turetsky DM, Buisson A, Choi DW (1995) The metabotropic glutamate receptor agonist, $4 \mathrm{C} 3 \mathrm{HPG}$, reduces kainate-induced death of cortical neurons expressing calcium-permeable AMPA/kainate receptors. Soc Neurosci Abstr 21:529.20.

Winder DC, Conn PJ (1993) Activation of metabotropic glutamate receptors increases cAMP accumulation in hippocampus by potentiating responses to endogenous adenosine. J Neurosci 13:38-44.

Winder DG, Ritch PS, Gereau IV RW, Conn PJ (1996) Novel glialneuronal signalling by activation of $\S$-adrenergic receptors in hippocampus. 2nd International Meeting on Metabotropic Glutamate Receptors. Neuropharmacology 35:A34. 